\title{
Tumor del saco vitelino de testículo en un niño de dos años de edad con criptorquidia izquierda: reporte de un caso
}

Testicular yolk sac tumor in a 2-year-old boy with left cryptorchidism: a case report

Tumor do saco vitelino testicular em um menino de dois anos com criptorquidia esquerda: relato de caso

\author{
Edgar Alfredo Carcasi-Laura ${ }^{1 a}$ \\ Víctor Hugo Quispe-Montesinos ${ }^{2 b}$ \\ Juan José Carpio-Cornejo ${ }^{20}$
}

(iD) https://orcid.org/0000-0001-5678-8624
(iD) https://orcid.org/0000-0002-0278-7201
(iD https://orcid.org/0000-0002-0026-4351

\section{Resumen}

El cáncer de testículo es un tumor maligno muy raro en prepúberes menores de 15 años de edad con una incidencia de 1/1000 000. El tumor del saco vitelino de testículo, es el tipo de tumor de células germinales de testículo (TCGT) más frecuente en niños menores de 2 años de edad. Caso clínico: Niño de 2 años y 5 meses de edad con criptorquidia izquierda, que presentó, desde hace seis meses, aumento progresivo de una tumoración ubicada en toda la ingle izquierda; caracterizada por ser de consistencia dura, indolora y no mostrar cambios de coloración en la piel supra yacente. En los exámenes auxiliares, la ecografía muestra: gran masa sólida, ovoide, de ecogenicidad heterogénea y múltiples cavidades anecoicas. El único marcador tumoral que presentó aumento fue la Alfafetoproteína (AFP): $12845,00 \mathrm{ng} / \mathrm{mL}$. El diagnóstico presuntivo fue de tumor maligno de testículo hasta que se demuestre lo contrario. Se le realiza orquiectomía inguinal radical con evolución postquirúrgica satisfactoria. Conclusión: el tumor testicular maligno en varones prepúberes menores de 15 años es muy raro, y el tipo de TCGT más frecuente en niños menores de dos años es el tumor del saco vitelino.

Palabras clave: cáncer de testículo, tumor del saco vitelino, niños, prepúberes

\begin{abstract}
Testicular cancer is a very rare malignant tumor in prepubescent males younger than 15 -year-old with an incidence of $1 / 1000000$. Testicular yolk sac tumor is the most common type of testicular germ cell tumor (TCGT) in children younger than 2-year-old. Clinical case: Child of 2-year-old and five months with cryptorchidism left, which presented, six months ago, progressive increase of a tumor located in the entire left groin; characterized by being of hard consistency, painless and show no discoloration changes in the overlying skin. Results: In the auxiliary examinations, the ultrasound showed: large solid mass, ovoid, heterogeneous echogenicity and multiple anemic cavities. The only tumor marker with an increase was Alpha-fetoprotein (AFP): $12845.00 \mathrm{ng} / \mathrm{mL}$. The presumptive diagnosis was of malignant testicular tumor until proven otherwise. Radical inguinal orchiectomy is performed with satisfactory postsurgical evolution. Conclusion: Malignant testicular tumor in prepubescent males younger than 15-year-old is very rare, and the most common type of TCGT in children younger than 2-yearold is yolk sac tumor.
\end{abstract}

Keywords: testicular cancer, yolk sac tumor, children, prepubescent

\footnotetext{
${ }^{1}$ Universidad Nacional Jorge Basadre Grohmann. Facultad de Ciencias de la Salud. Tacna, Perú

${ }^{2}$ Hospital III Daniel Alcides Carrión - EsSalud Tacna. Tacna, Perú

${ }^{a}$ Médico urólogo

${ }^{\mathrm{b}}$ Médico patólogo

'Médico cirujano pediatra
} 


\section{Resumo}

O câncer de testículo é um tumor maligno muito raro em pré-púberes menores de 15 anos de idade com uma incidência de 1/1 000 000. O tumor do saco vitelino testículo, é o tipo de tumor de células germinativas testiculares (TCGT) mais freqüente em crianças com menos de 02 anos de idade. Caso clínico: Criança de 02 anos e 05 meses de idade com criptorquidia esquerda, que apresentou, há seis meses, aumento progressivo de uma tumoração localizada em toda a virilha esquerda; caracterizada por ser de consistência dura, indolor e não apresentar alterações de coloração na pele adjacente. Resultados: Nos exames auxiliares, a ecografia mostra: grande massa sólida, ovóide, de ecogenicidade heterogênea e múltiplas cavidades Anecóicas. O único marcador tumoral que apresentou aumento foi a Alfafetoproteína (AFP): $12845,00 \mathrm{ng} / \mathrm{mL}$. O diagnóstico presumido foi de tumor maligno no testículo até que se prove o contrário. A orquiectomia inguinal radical é realizada com evolução pós-cirúrgica satisfatória. Conclusão: o tumor testicular maligno em machos prépúberes menores de 15 anos é muito raro, e o tipo de TCGT mais freqüente em crianças menores de dois anos é o tumor do saco vitelino.

Palavras-chave: câncer de testículo, tumor do saco vitelino, crianças, pré-púberes

\section{Introducción}

El cáncer de testículo es un tumor maligno muy raro con una incidencia de $1 / 1000$ 000 en prepúberes menores de 15 años de edad, ${ }^{1}$ comprende solo el $4 \%$ de los cánceres infantiles. ${ }^{2,3}$ La mortalidad es baja en la infancia, la supervivencia en el cáncer testicular prepuberal es del $99 \%$ a los 5 años. ${ }^{4}$ El cáncer de testículo en prepúberes menores de 15 años presenta una ligera predominancia en los de raza blanca, ${ }^{1}$ y es 3,7 a 7,5 veces mayor en pacientes con criptorquidia que pacientes con testículos en sus respectivas bolsas escrotales.

El tumor del saco vitelino, también conocido como tumor del seno endodérmico, es el TCGT más frecuente en niños menores de 2 años. ${ }^{6}$ En prepúberes el tumor del saco vitelino de testículo normalmente es de forma pura. ${ }^{7}$ El marcador tumoral AFP se encuentra aumentada en 95 al $98 \%$ de los casos, este marcador tumoral se utiliza para su diagnóstico y seguimiento; así como, para evaluar la regresión o recurrencia del tumor. ${ }^{8}$ En cuanto a la ecografía, generalmente vamos a tener como hallazgo: una gran masa sólida, homogénea, hipoecoica, redonda u ovoide, focal o difusa; pudiendo ocupar por completo el testículo afectado $y$, a veces, sólo muestra un agrandamiento difuso testicular; es raro encontrar áreas heterogéneas con necrosis y calcificaciones. ${ }^{9,10}$ En la ecografía Doppler color suelen ser tumores hipervasculares y en la elastografía ecográfica son lesiones predominantemente rígidas. $^{11}$

El objetivo del presente estudio, es destacar que el TCGT es muy raro en varones prepúberes, y el tumor del saco vitelino de testículo es más frecuente en niños menores de 2 años de edad.

\section{Caso clínico}

Paciente de sexo masculino de 2 años y 5 meses de edad, procedente y natural del departamento de Puno, padres consultan por tumoración inguinal izquierda que presenta aumento progresivo de tamaño desde hace 6 meses (Figura 2). Tiene el antecedente de ser recién nacido a término con criptorquidia izquierda; niegan antecedentes de enfermedades crónicas, infecciones virales o bacterianas, traumatismos, cirugías previas y antecedentes heredofamiliares. Al examen físico: tumoración que ocupa toda la ingle izquierda, de consistencia dura, no dolorosa a la palpación, ni cambios de coloración en la piel suprayacente; además, ausencia de testículo en bolsa escrotal homolateral; el testículo derecho de aparentes características normales y ubicado en su bolsa escrotal correspondiente. El examen ecográfico muestra: una gran masa sólida con ecogenicidad heterogénea, con múltiples cavidades anecoicas, ovoide, de 
$6 \times 5 \times 4,5 \mathrm{~cm}$ de volumen aproximadamente, y que ocupa la totalidad del canal inguinal izquierdo, no pudiendo distinguir el epidídimo; testículo y epidídimo derecho de características ecográficas normales (Figura 3). Los marcadores tumorales muestran los siguientes resultados: AFP de $12845,00 \mathrm{ng} / \mathrm{mL}$, hormona gonadotrofina coriónica menor de 0,5 micro $\mathrm{UI} / \mathrm{mL}$, deshidrogenasa láctica de 266,00 U/L. El diagnóstico presuntivo fue de tumor maligno de testículo hasta que se demuestre lo contrario. Se somete a cirugía realizándole un orquiectomía radical izquierda por vía inguinal (Figura 4), y se envía pieza operatoria a anatomía patológica. Luego de los resultados de Anatomía Patológica (Tabla 1), se le deriva a Oncología Médica para continuar con los estudios de extensión y posterior manejo de manera multimodal.

\section{Figura 1}

Cronología de la evolución de la enfermedad

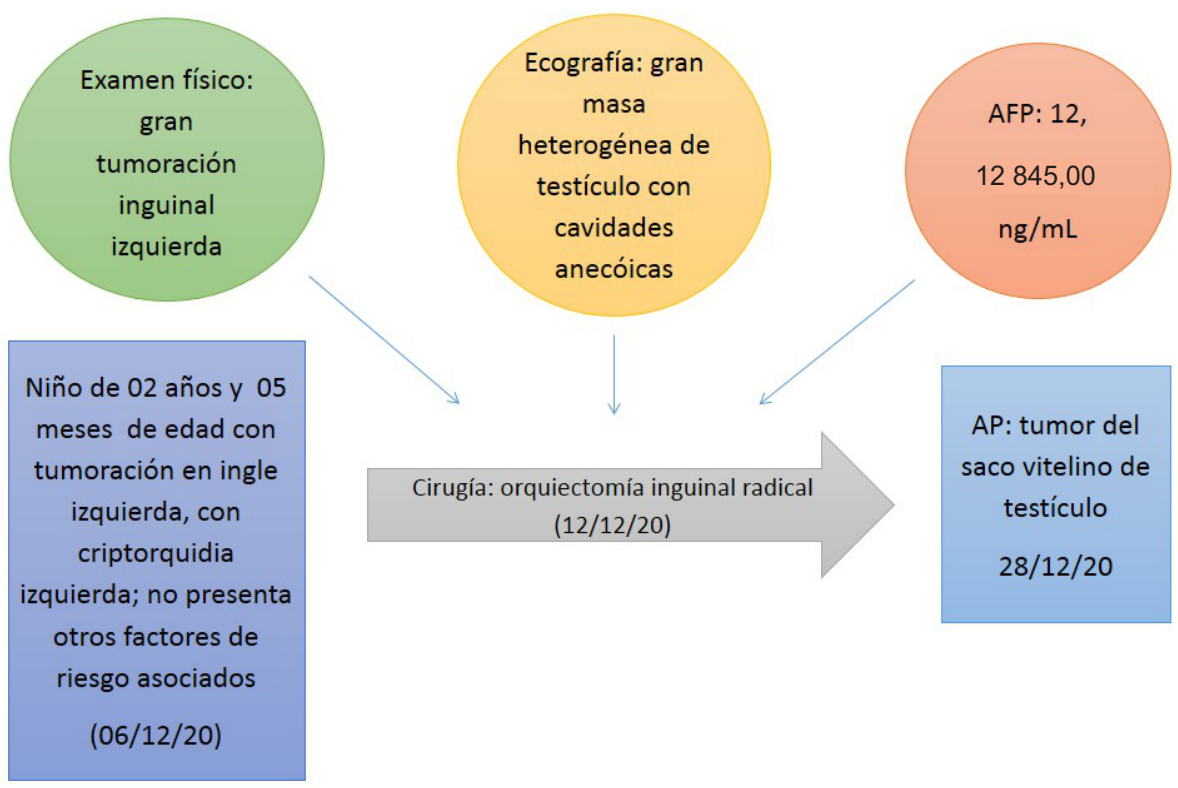

\section{Figura 2}

\section{Tumoración inguinal izquierda}

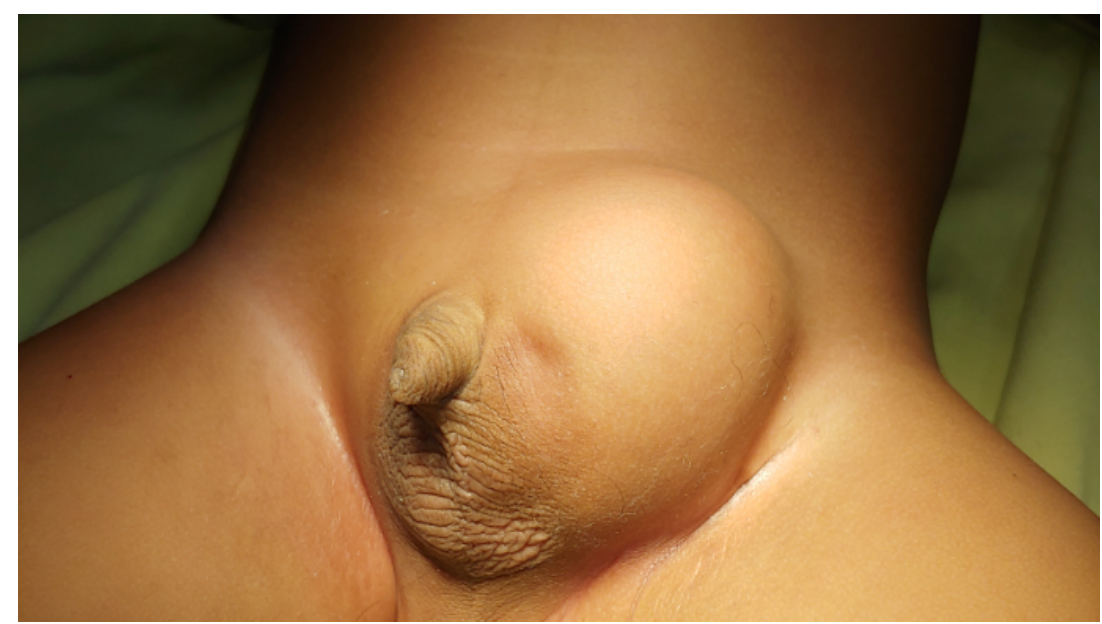




\section{Figura 3}

Ecografía testicular: masa sólida con multiples cavidades anecoicas

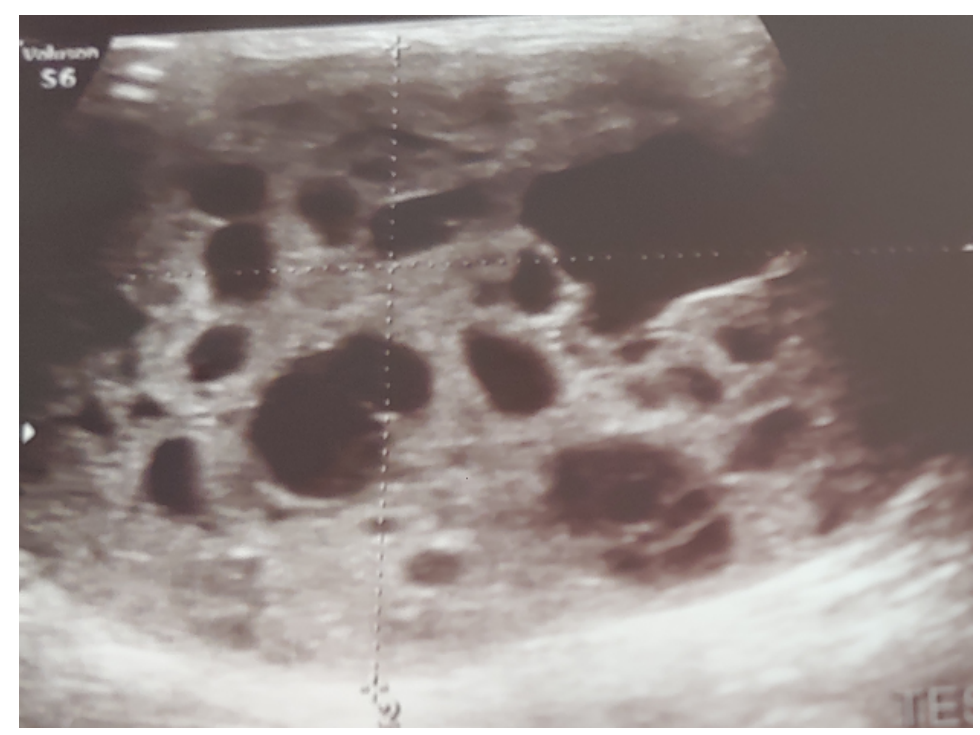

\section{Figura 4}

Orquiectomía inguinal radical izquierdo

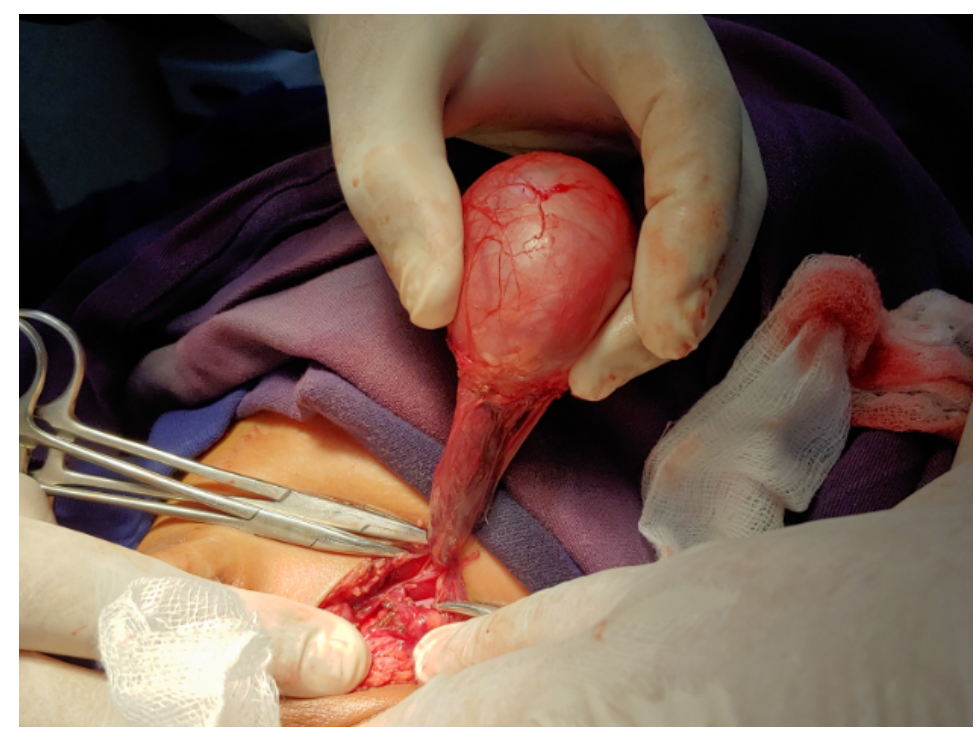

\section{Tabla 1}

Resultados de anatomía patológica

\begin{tabular}{lc}
\hline Espécimen: & Testículo izquierdo y anexos \\
Tamaño tumoral: & $5.9 \times 4.8 \times 4.5 \mathrm{~cm}$ \\
Tipo histológico: & Tumor del saco vitelino prepuberal \\
Extensión tumoral: & Tumor invade la rete testis \\
Conducto deferente: & Libre de neoplasia \\
Invasión linfovascular: & Presente \\
Estadiaje patológico: & pT2 Nx Mx \\
\hline
\end{tabular}




\section{Discusión}

El tumor del saco vitelino de testículo en la mayor parte de los casos se presenta en niños menores de 2 años de edad, ${ }^{11-13}$ representa el 70 al $80 \%$ de las neoplasias testiculares en la infancia. ${ }^{14,15}$ El paciente fue evaluado y diagnosticado a los 2 años y 5 meses de edad; sin embargo, su madre refiere aumento progresivo, desde hace 6 meses, de dicha tumoración en la zona inguinal izquierda. Al examinar a estos pacientes típicamente presentan un incremento del tamaño de testículo, que generalmente son asintomáticos y se recomienda no guiarnos de la transiluminación; puesto que, un hidrocele puede estar asociado a un tumor en 15 a $25 \%$ de los casos. ${ }^{16,17}$ El paciente presentó incremento de testículo ubicado en zona inguinal izquierda, no doloroso a la palpación y no se utilizó transiluminación. Los tamaños notificados del tumor en la infancia han oscilado entre 2 y $11 \mathrm{~cm}$ de diámetro. ${ }^{15,16}$ El tumor del saco vitelino de testículo y su aspecto ecográfico no es específico, generalmente se encuentra una masa sólida homogénea., ${ }^{9,10}$ Puede tener un patrón heterogéneo incluso con espacios anecoicos. ${ }^{17,19}$ El marcador tumoral que se incrementa frecuentemente es la AFP, ${ }^{3,8}$
En relación al paciente, ecográficamente presentó una masa sólida heterogénea, con espacios anecoicos, y el único marcador tumoral que se incrementó fue la AFP. Los tumores del saco vitelino son de consistencia sólida de color blanco grisáceo con una apariencia gelatinosa, mixoide o mucoide. Frecuentemente, se observan cambios quísticos, necrosis y hemorragias; la apariencia general de los tumores del saco vitelino es heterogénea. Microscópicamente los cuerpos de Schiller-Duval son una característica fundamental de los tumores del saco vitelino, y se observan en el 50 a $75 \%$ de los casos..$^{20} \mathrm{En}$ el paciente se encontró macroscópicamente: un tumor gris a amarillo, heterogéneo, sólido con múltiples quistes, con hemorragia focal, no se puede diferenciar epidídimo (Figura 5). Microscópicamente: presenta patrón reticular microquístico; caracterizado por una red de canales anastomóticos que se expanden focalmente para formar quistes de tamaño variable. Los microquistes contienen glóbulos hialinos eosinofílicos y material de membrana basal acelular eosinofílica amorfa en un estroma suelto, hipocelular y mixoide (Figuras 6 y 7$)$.

\section{Figura 5}

Tumor testicular heterogéneo, sólido quístico, pardo gris amarillento, que reemplaza en su totalidad a gónada masculina

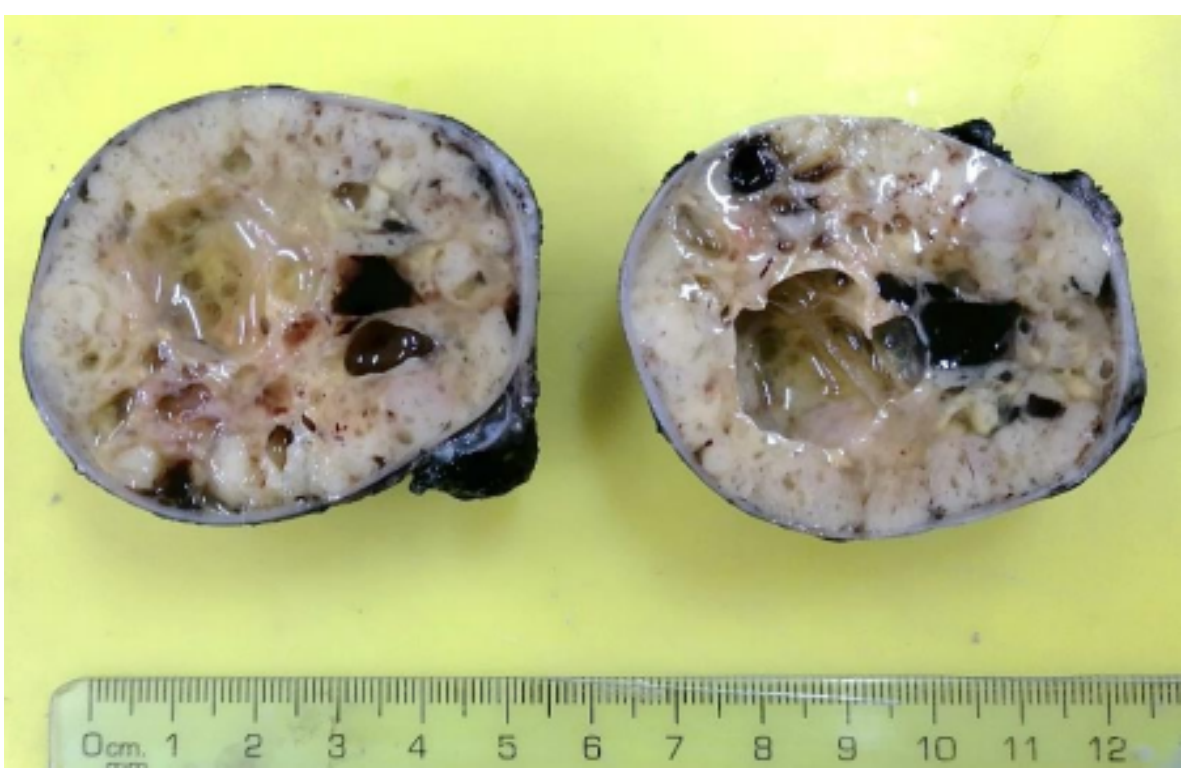




\section{Figura 6}

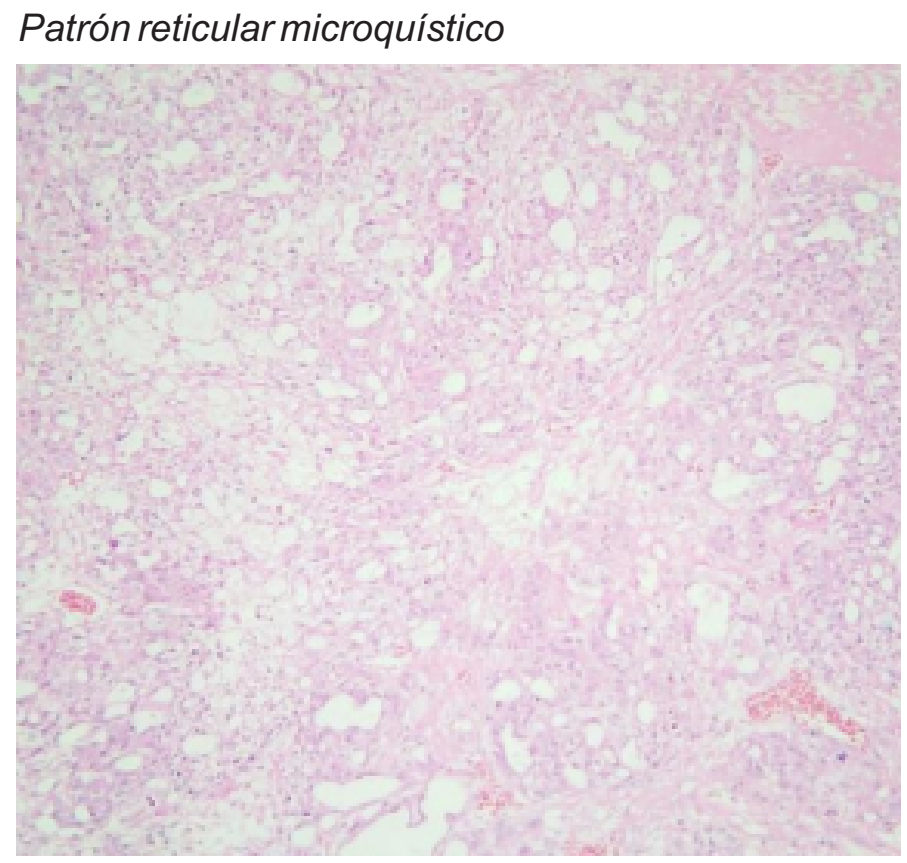

\section{Figura 7}

Patrón reticular microquístico: en el extremo superior izquierdo, se observa área necrohemorrágica; hallazgo encontrado en varios focos del tumor.

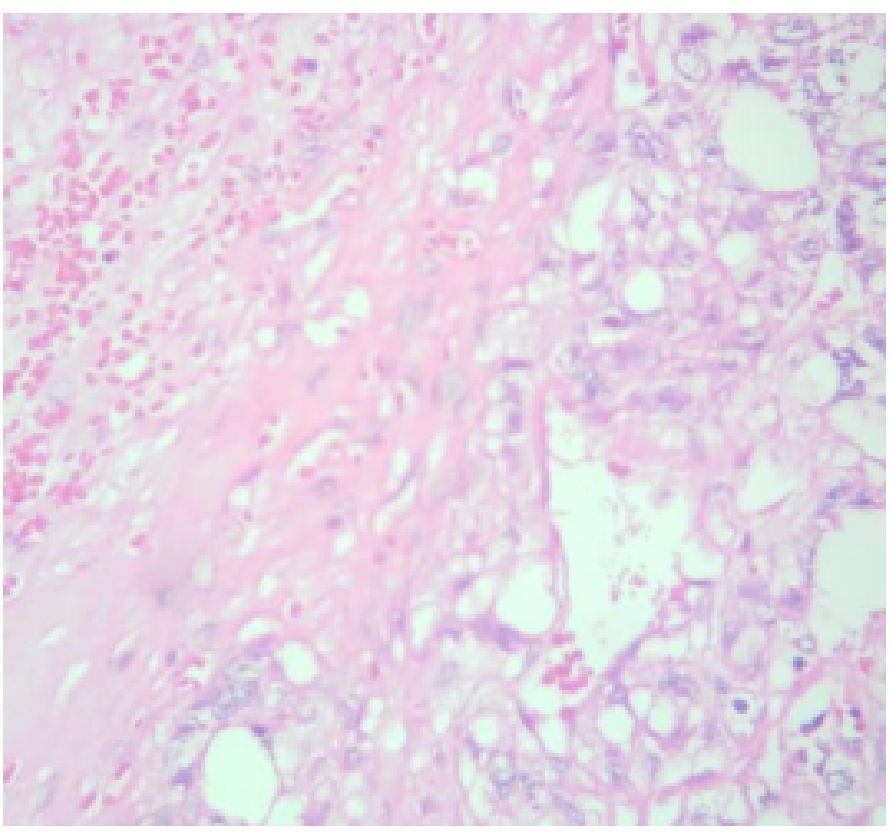

\section{Conclusión}

El tumor testicular maligno en varones prepúberes menores de 15 años es muy raro, y el tipo de TCGT más frecuente en niños menores de dos años es el tumor del saco vitelino.

\section{Referencias}

1. Young JL, Ries LG, Silverberg E, Horm JW, Miller RW. Cancer incidence, survival, and mortality for children younger than age 15 years. Cancer. 1986; $58(S 2): 598-602$. 
https://doi.org/10.1002/10970142(19860715)58:2+\%3C598::AIDCNCR2820581332\%3E3.0.CO;2-C

2. Kusler KA, Poynter JN. International testicular cancer incidence rates in children, adolescents and young adults. Cancer Epidemiol. 1 de octubre de 2018; $56: 106-11$ D O I: 10.1016/j.canep.2018.08.002

3. Steliarova-Foucher E, Colombet M, Ries LAG, Moreno F, Dolya A, Bray F, et al. International incidence of childhood cancer, 2001-10: a population-based registry study. Lancet Oncol. 1 de junio de 2017 ; 18 ( 6 ): $719-31$. https://doi.org/10.1016/S14702045(17)30186-9

4. Ahmed HU, Arya M, Muneer A, Mushtaq I, Sebire NJ. Testicular and paratesticular tumours in the prepubertal population. Lancet Oncol. 1 de mayo de 2010;

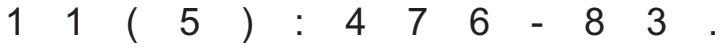
https://doi.org/10.1016/S14702045(10)70012-7

5. Thorup J, McLachlan R, Cortes D, Nation TR, Balic A, Southwell BR, et al. What is new in cryptorchidism and hypospadias-a critical review on the testicular dysgenesis hypothesis. J Pediatr Surg. 1 de octubre de $2010 ; 45(10): 2074-86$. https://doi.org/10.1016/j.jpedsurg.2010.07 .030

6. Sangüesa C, Veiga D, Llavador M, Serrano A. Testicular tumours in children: an approach to diagnosis and management with pathologic correlation. Insights Imaging. 27 de mayo de 2020; 11(1):74. https://doi.org/10.1186/s13244-02000867-6

7. Williamson SR, Delahunt B, Magi-Galluzzi C, Algaba F, Egevad L, Ulbright TM, et al. The World Health Organization 2016 classification of testicular germ cell tumours: a review and update from the International Society of Urological Pathology Testis Consultation Panel. Histopathology. 2017; 70(3):335-46. https://doi.org/10.1111/his.13102
8. Talerman A, Haije WG, Baggerman L. Serum alphafetoprotein (AFP) in patients with germ cell tumors of the gonads and extragonadal sites: Correlation between endodermal sinus (yolk sac) tumor and raised serum AFP. Cancer. 1980; 46(2):380-5. https://doi.org/10.1002/10970142(19800715)46:2\%3C380::AIDCNCR2820460228\%3E3.0.CO;2-U

9. Song Q-D. Ultrasound Appearances of Pediatric Testicular Yolk Sac Tumors: Twenty-one Cases in a Single Institution. J Ultrasound Med. 2018; 37(10):2457-63. https://doi.org/10.1002/jum.14597

10. Aso C, Enríquez G, Fité M, Torán N, Piró C, Piqueras J, et al. Gray-Scale and Color Doppler Sonography of Scrotal Disorders in Children: An Update. RadioGraphics. 1 de septiembre de 2005; 25(5):1197-214. https://doi.org/10.1148/rg.255045109

11. Fang C, Huang DY, Sidhu PS. Elastography of focal testicular lesions: current concepts and utility. Ultrasonography. Octubre de 2019 ; $38(4): 302-10$. https://doi.org/10.14366/usg.18062

12. Xu H-X, Yi X-P. Sonographic appearance of a testicular yolk sac tumor in a 2-year-old boy. J Clin Ultrasound. 2007; 35(1):55-7. https://doi.org/10.1002/jcu.20249

13. Teixeira RL, Rossini A, Paim NP. Tumores testiculares na infância. Rev Colégio Bras Cir. Febrero de 2009; 36(1):85-9. http://dx.doi.org/10.1590/S010069912009000100015.

14. Thava V, Cooper N, Egginton JA. Yolk sac tumour of the testis in childhood. $\mathrm{Br} \mathrm{J}$ Radiol. 1 de diciembre de 1992; $65\left(\begin{array}{lll}7 & 8 & 0\end{array}\right): \begin{array}{llllll}1 & 1 & 4 & 2 & - & 4\end{array}$. https://doi.org/10.1259/0007-1285-65780-1142

15. Cox L, Donald JC, Machin GA, Popkin JS, Zacks D. Intraabdominal testis with yolk sac tumor in a 2-year-old child. J Pediatr Surg. 1 de agosto de 1988; 23(8):775-6. https://doi.org/10.1016/S00223468(88)80425-1

16. Ross Martin M., Morrow James W. Yolk Sac Carcinoma of the Testis. J Urol. 1 de julio de 
$1972 ; 108(1): 109-11$. https://doi.org/10.1097/pas.00000000000 00322

17. Dogra VS, Gottlieb RH, Oka M, Rubens DJ. Sonography of the Scrotum. Radiology. 1 de abril de 2003; 227(1):18-36. https://doi.org/10.1148/radiol.2271001744

18. Young PG, Mount BM, Foote FW, Whitmore WF. Embryonal adenocarcinoma in the prepubertal testis. A Clinicopathologic Study of 18 Cases. Cancer. $1970 ; 26(5): 1065$ 75.https://doi.org/10.1002/10970142(197011)26:5\%3C 1065::AIDCNCR2820260515\%3E3.0.CO;2-K
19. Ultrasonography of Testicular Tumors Abstract - European Urology 1990, Vol. 17, No. 4 - Karger Publishers [Internet]. 2021 [citado 21 de enero de 2021]. Disponible e $n$ https://www.karger.com/Article/Abstract/4 64058

20. Arumugam D, Thandavarayan $P$, Chidambaram L, Boj S, Marudasalam S. Primary Nasopharngeal Yolk Sac Tumor: A Case Report. J Clin Diagn Res JCDR. Mayo de 2016; 10(5):ED06-7. DOI: 10.7860/JCDR/2016/17620.7760

\section{Correspondencia:}

ecarcasilaura1@gmail.com
Fecha de recepción: 15/12/2020

Fecha de aceptación: 28/01/2021 